\title{
Rohingya Crisis: An Added Challenge in Neurosurgical Arena of Chattogram Medical College Hospital
}

\author{
Karim $\mathbf{R}^{1}$, Chowdhury $\mathrm{SMNK}^{2}$, Mainuddin $\mathrm{SM}^{3}$, Khan $\mathrm{Al}^{4}$, Islam $\mathrm{MM}^{5}$, Alam $\mathbf{S}^{6}$, \\ Quader $\mathbf{M}^{7}$, Rashid $\mathbf{H}^{8}$
}

Conflict of interest: There is no conflict of interest relevant to this paper to disclose.

Funding Agency : was not funded by any institute or any group.

Contribution of Authors :

Principal Investigator -Dr. Md. Rabiul Karim

Data collection- Prof. SM Noman Khaled Chowdhury, Dr. Anisul Islam Khan, Dr. Manzoorul Islam

Manuscript preparation- Prof. S.M

Mainuddin Dr. Md. Saiful Alam

Editorial formatting- Dr. Mahfuzul

Quader, Dr. Humayun Rashid

Copyright: @2020bang.BJNS published by BSNS. This article is published under the creative commons CC-BY-NC license. This license permits use distribution (https://creativecommons. orgf/licences/by-nc/4-0/)reproduction in any medium, provided the original work is properly cited and is not used for commercial purposes.

Received: 07 Aug 2019

Accepted: 12 September 2019

\begin{abstract}
:
Rohingya are the group of people who has an specific ethnic, linguistic and religious group lived in the former Arakan state, renamed as Rakhain state of Myanmar. These people are homeless, stateless and disowned by their own government.
\end{abstract}

Chattogram Medical College Hospital is the only tertiary level government hospital nearest to the Rohingya camp where Rohingya patients are referred from local health care providers. On a cross sectional observational demographic study conducted in the Department of Neurosurgery, $\mathrm{CMCH}$ revealed that, total number of admitted patient in CMCH is 757 among which 137 (18.09\%) patient was admitted in Department of Neurosurgery since the Rohingya citizens are forcibly displaced from their land. Traumatic brain injury (31), spinal injury (22) and gun shot wound (3) are the most common presentation as a result of ethnic cleansing. But lack of primary health care support, proper health education leads to development of hydrocephalus (8), meningocele (8), meningomyelocele (1) in children and delayed presentation of ICSOL (15) and Spinal SOL (2) are also observed among the admitted patients. 67 (48.90\%) patients were treated conservatively and 70 (51.09\%) patients are treated operatively.

Despite the existing over crowded patients from the Chattogram Division, these Rohingya patients made an added challenge to the Department of Neurosurgery. Proper strategic plan should be carried out for the management of neurosurgical condition for decreasing mortality and morbidity and thus support humanity above all.

Keywords: \# Rohingya Crisis \# $\mathrm{CMCH}$ \# Rohingya in $\mathrm{CMCH}$.

Bang. J Neurosurgery 2020; 9(2): 111-116

\section{Introduction}

Rohingya is the term used to discriminate a racial, linguistic and religious group who lived in the former Arakan state, renamed as Rakhain state of Myanmar. Chattogram Medical College Hospital is the only tertiary level government hospital nearest to the Rohingya camp where Rohingya patients are referred from local health care providers. Lack of nutrition, health education, immunization, maternal and new born child health carealong with existing mass attack by beating and arms like rifle, bullet, bomb blast by the Myanmar army leads to various neurosurgical conditions that need to be addressed by the Department of Neurosurgery, Chattogram Medical College Hospital as an urgent basis.

1. Dr. Md. Rabiul Karim, Assistant Professor, Department of Neurosurgery, Chattogram Medical College Hospital.

2. Prof. SM Noman Khaled Chowdhury, Professor \& Head, Department of Neurosurgery, Chattogram Medical College Hospital.

3. Prof. Syed Md. Mainuddin, Professor, Department of Neurosurgery, Chattogram Medical College Hospital.

4. Dr. Anisul Islam Khan, Associate Professor, Department of Neurosurgery, Chattogram Medical College Hospital.

5. Dr. Md. Manzoorul Islam, Associate Professor, Department of Neurosurgery, Chattogram Medical College Hospital.

6. Dr. Md. Saiful Alam, Assistant Professor, Department of Neurosurgery, Chattogram Medical College Hospital.

7. Dr. Mahfujul Quader, Assistant Professor, Department of Neurosurgery, Chattogram Medical College Hospital.

8. Dr. Humayun Rashid, Resident, Department of Neurosurgery, Chattogram Medical College Hospital.

Address of Correspondence: Dr. Md. Rabiul Karim, Assistant Professor, Department of Neurosurgery, Chattogram Medical College Hospital, Phone: +01711748893, E-mail: rkarim_31st@yahoo.com 


\section{Background:}

Rohingya people are homeless, stateless and disowned by their own government with the argument that they are not Myanmar citizens rather came from Bangladesh ${ }^{1}$. Forcibly Displaced Myanmar Nationals (FDMNs) were first seen in 1978 and again in 1991-1992². Almost 250,000 people migrated to Bangladesh during these two periods. ${ }^{3} \mathrm{UN}$ officials and HRW have described Myanmar's persecution of the Rohingya as ethnic cleansing which began in 2017 and since august 25, 2017 approximately 1.1 million Rohingyas have arrived in Ukhiya, Coxsbazar, Bangladesh ${ }^{3,4}$. World Health Organization (WHO) has graded this crisis as a level 3 emergency based on the public health situation and added challenge to health care providers in Bangladesh ${ }^{5}$.These people escaping violence in Myanmar's Rakhain state have crossed the MyanmarBangladesh border since the end of August 2017 when HPM Sheikh Hasina unbolts the border on humanitarian ground. Approximately 1.1 million Rohingyawhich include 585000 in the Kutupalong Expansion site, 237000 in other settlements and camps, and 79000 in host communities, who have joined another 213000 Rohingya people already in Bangladesh following earlier waves of displacement. The speed and scale of the influx has resulted in a critical humanitarian emergency, with peoplerelying almost entirely on humanitarian assistance for food, water, shelter and basic needs.

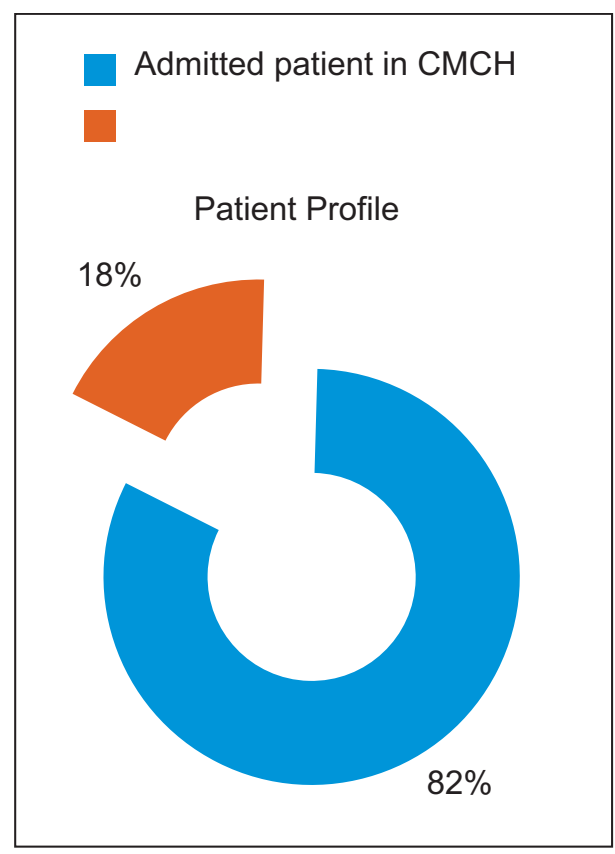

Methods:

- Type of Study: Hospital based observational cross sectional study

- Place of Study: Department of Neurosurgery, Chattogram Medical College Hospital

- Study Period: 1 year 6 month

- Study Population: All Rohingya patients admitted in Department of Neurosurgery, $\mathrm{CMCH}$

- Sampling: Purposive sampling

\section{Results:}

Demographic Sample Description

Between $12^{\text {th }}$ August 2017 and 20th March 2019, 757 Rohingya patient were admitted in Chattogram Medical College Hospital. Among them 137 patient were admitted in the Department of Neurosurgery.

Sex: The sample consisted of 91 (66\%) Male and 46 (33\%) Female.

Age:Their age ranged from 1 day to 91 years with a median of 17 . More than half the sample $(59 \%)$ was below the age of 18 years. One third (36\%) was Adult (19-59 years). The largest age group, or the mode ( $40 \%$ of the sample) was child ( $0-12$ years) group.

Marital Status: Being majority belongs to the child group, 79 (58\%) were un-married, 19 (26\%) were married and 40 (29\%) were single, among them 34 were widowed and 6 were divorced.

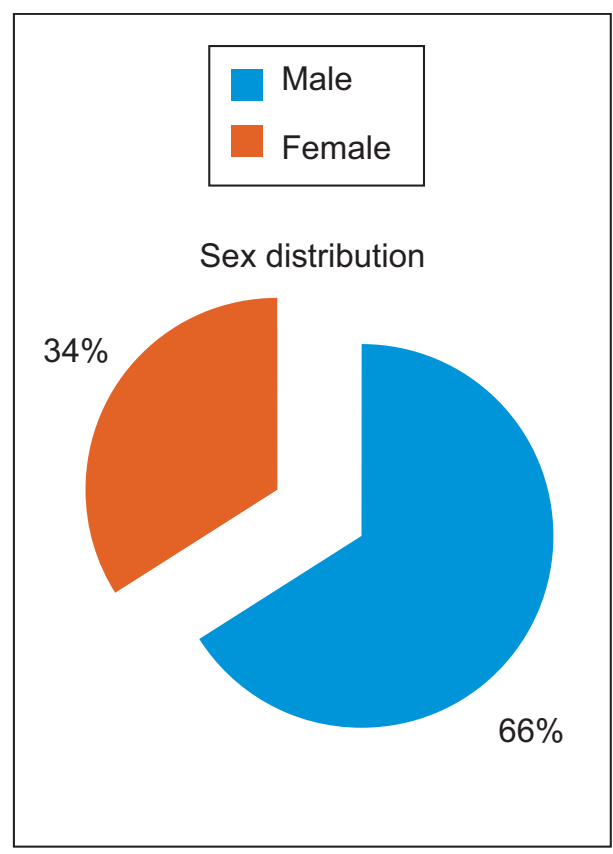


Educational Background: 98 (72\%) were found uneducated, $17(13 \%)$ has primary education, 12 (8\%) has education up to 12 class (Higher secondary education), and 10 (7\%) can only write their name.

Disease Profile:Among the total patient $82(60 \%)$ were brain cases and $52(38 \%)$ were spine cases and $3(2 \%)$ were other (Gun shot wound) cases.
Nature of Treatment: 67 (49\%) patients received conservative treatment and $70(45 \%)$ received operative treatment. Total9 $(7 \%)$ patient died before getting definitive (Conservative or surgical) treatment. $8(6 \%)$ patient were absconded after getting treatment from the hospital.
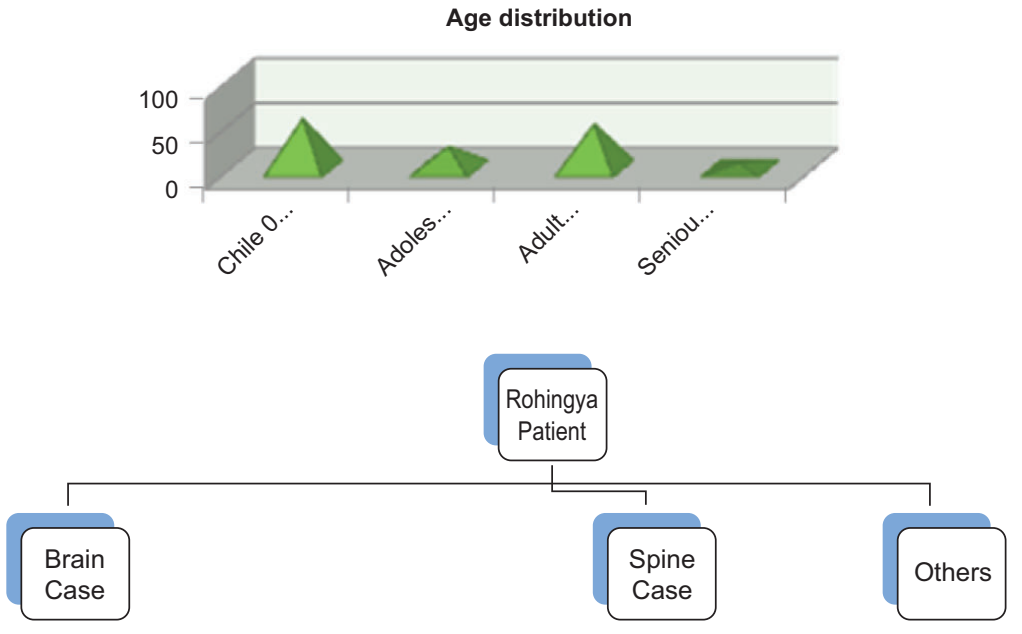

1. Mild Head Injury: 31

ICSOL: 15

Hydrocephalus: 8

Compound Depressed \#: 6

Haemorrhagic Stroke: 6

Extra Dural Haematoma: 3

Encephalocele: 2 (Frontal 1, Occipital 1)

Anencephaly 2

Diffuse Axonal Injury: 1

Cerebral Abcess : 1

Subdural Empyema: 1

Meningoencephalitis: 1

Sub arachnoid Haemorrhage: 1

Haemangioma in skull: 1

Osteoma: 1

Encephalitis: 1

Osteomyelitis: 1

Total: $82(60 \%)$

\section{Rohingya Patient}

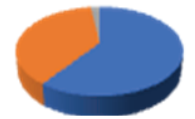

1. Spinal Injury: 22 1.Gun shot wound : 3

2. Lumbago e Sciatica (PLID): 9

3. L/S Meningocele 8

4. Lumbago: 4

5. Pott's Disease: 3

6. Spinal SOL: 2

7. SCIWORA: 1

8. Myelomeningocele: 1

9. Meningocele e HCP: 1

10. Limited lumber myeloschisis: 1

Treatment

100

0

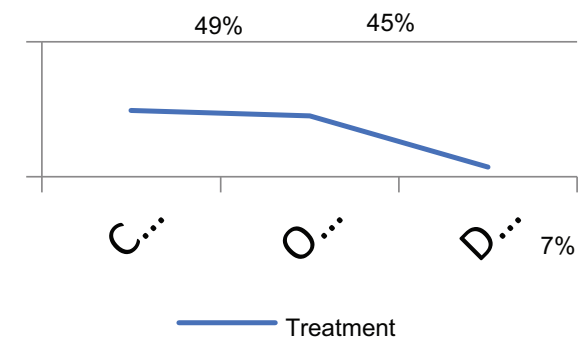


Typeof Operation Done :

\section{Brain:}

1. Craniotomy and Excision of ICSOL

2. CSF Diversion Procedure (V-P Shunt)

3. Elevation of Depressed fragment

4. Craniotomy and Evacuation of EDH

5. External Ventricular Drainage

6. Excision and repair of encephalocele

7. Excision of Haemangioma and reconstruction of skull

8. Incision, curettage and drainage of osteomyelitis

\section{Spine:}

1. Decompression and Stabilization

2. Fenestration and Discectomy

3. Excision, repair of L/S meningocele

4. Laminectomy and Decompression of tubercular abcess

5. Laminectomy and excision of Spinal SOL

6. Wound debridement and primary closure

\section{Discussion:}

This is a hospital based observational cross sectional study conducted for a period of 1 year and 3 month in the Department of Neurosurgery, Chattogram Medical College Hospital revealed that, total number of admitted patient in $\mathrm{CMCH}$ is 757 among which 137 (18\%) patient was admitted in Department of Neurosurgery since the Rohingya are forcibly displaced from their land. Traumatic brain injury (31), spinal injury (22), physical assault (9) andgunshot wound (3) are the most common presentation as a result of direct violence upon them.
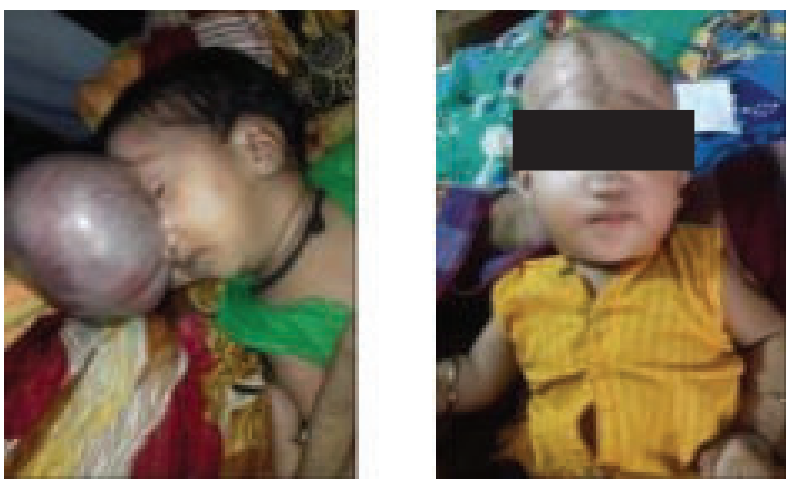

Fig: Frontal Encephalocele (Pre and Post Operative)

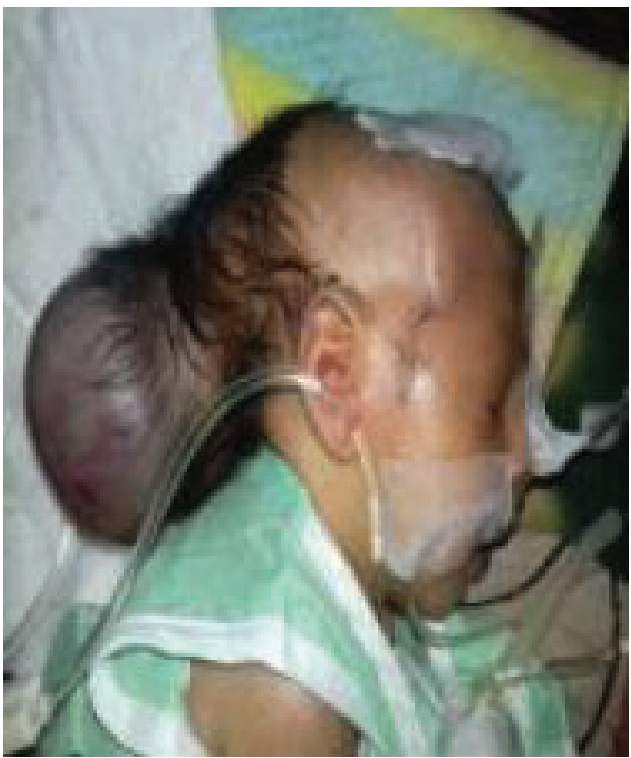

Fig: Occipital Encephalocele

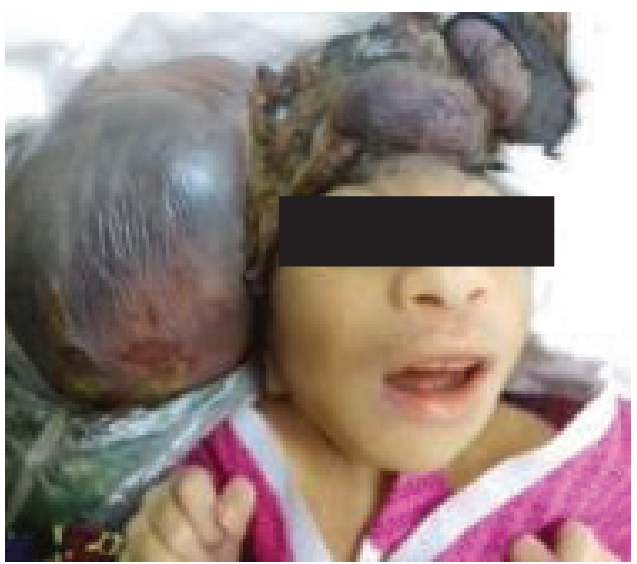

Fig: Anencephaly

Rohingyas are deprived of primary health care support, proper health education, ante natal checkup which leads to development of several new born child with developmental anomalies like hydrocephalus (8), meningocele (8), anencephaly (2), meningomyelocele (1), LLM (1). In this study, we also noticed that there is delayed presentation of ICSOL (15) and Spinal SOL (2) among the admitted patients.

In this study, we also noticed that there is delayed presentation of ICSOL (15) and Spinal SOL (2) among the admitted patients.

As the Government of Bangladesh opens the border for Forcibly Displaced Myanmar Nationalists (FDMNs), allocated 3000 acres of land in Kutupalong, Ukhiya, Coxsbazar for their shelter, sharing food, meeting basic 


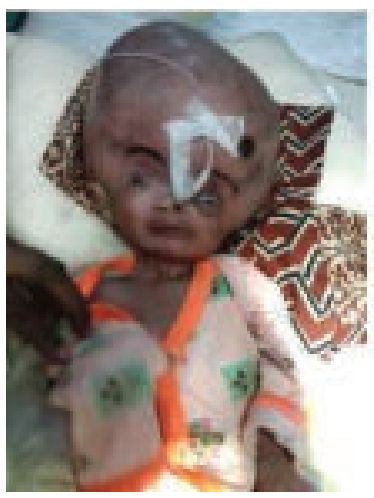

Fig: Hydrocephalus
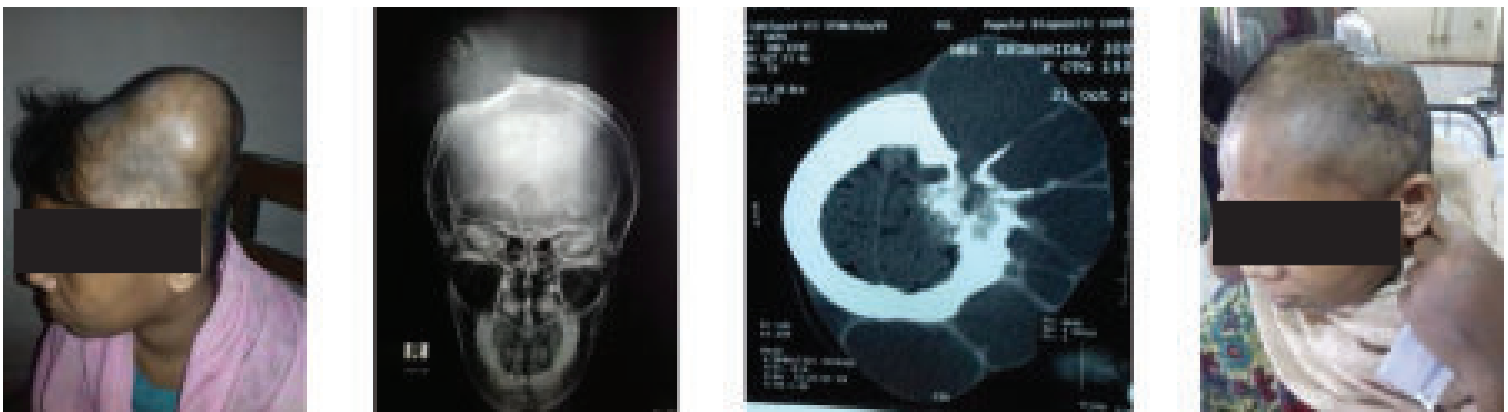

Fig : Metastatic adenocarcinoma of 30 Years Female Rohingya Patient
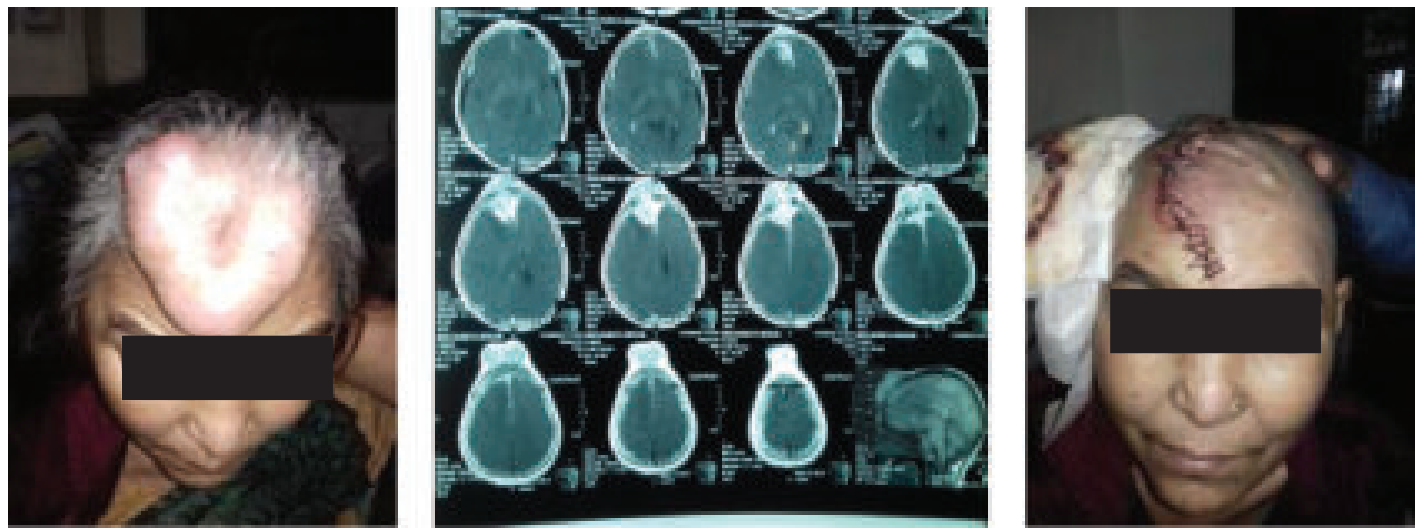

Fig : Meningothelial meningioma in a 50 Years Female Rohingya Patient
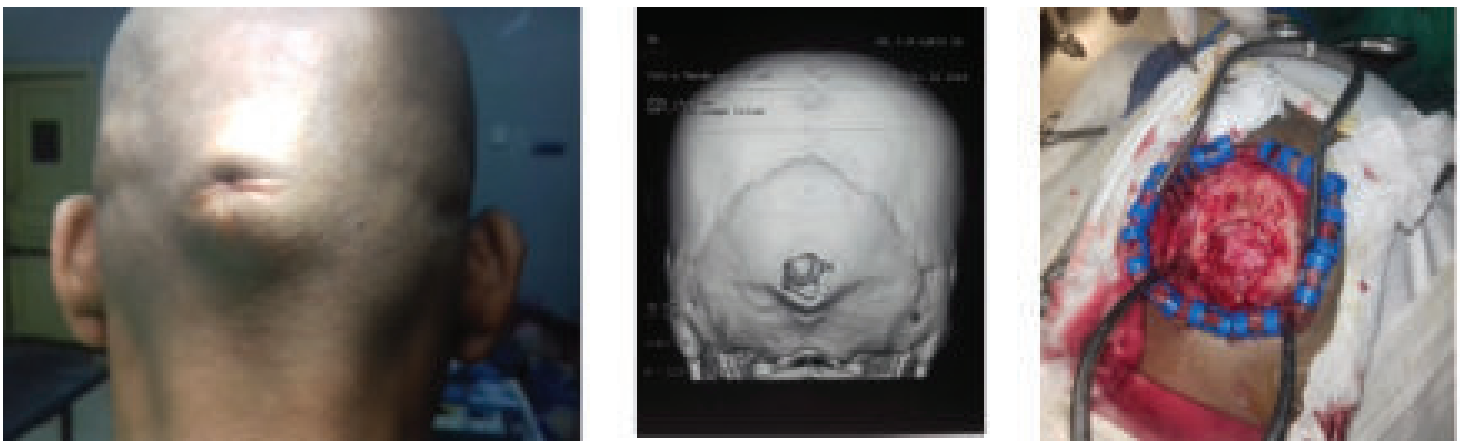

Fig : Chronic osteomyelitis of Skull due to old stock injury 

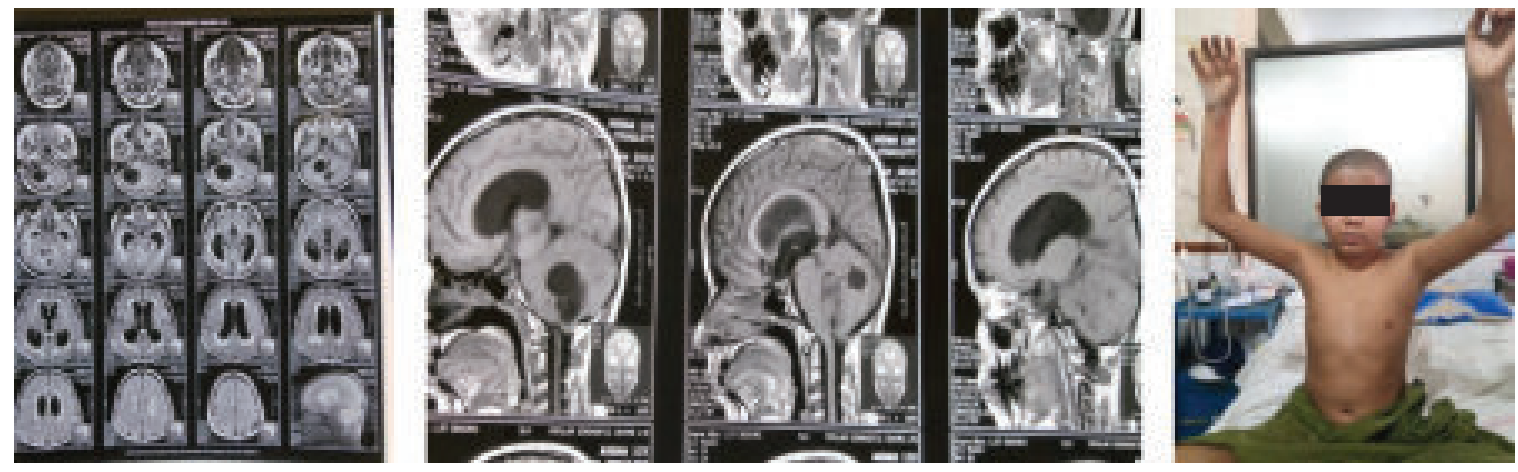

Fig : Cerebellar SOL in a 12 years Child with Post operative status on $5^{\text {th }}$ Day
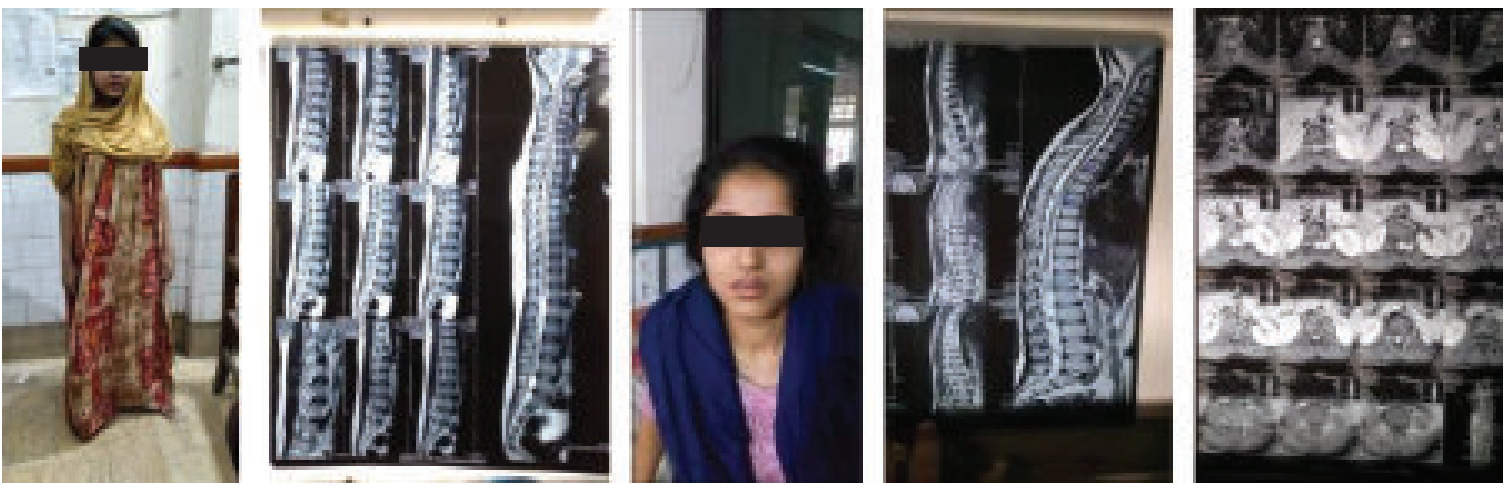

Fig : Spinal SOL (Schwannoma) Fig: Multiple Spinal SOL (Schwannoma)

needs with the help of local and international NGO's, alongside these people are getting treatment at free of cost from all the government hospitals. As a consequence of this government humanitarian effort, $67(49 \%)$ patients were treated conservatively and 70 (45\%) patients were treated operatively.During admission, $9(7 \%)$ patient died before getting definitive (Conservative or surgical) treatment. $8(6 \%)$ patient were found absconded after getting treatment from the hospital which is informed to hospital authority and local police camp.

\section{Conclusions:}

There are continued efforts taken to prevent largest humanitarian catastrophic epidemic outbreak of communicable diseases, water born diseases, blood born diseases, malnutrition, support for mental, sexual and reproductive health by the national and international NGO's but a large number of people are escaped from this group who needs neurosurgical management. Proper strategic plan should be carried out for the management of neurosurgical conditions to minimize mortality and morbidity and thus support humanity above all.

\section{Reference:}

1. Médecins Sans Frontières (MSF). (2010,February 18) Bangladesh: Violent crackdown fuels humanitarian crisis for unrecognized Rohingya refugees. Retrieved from http:/ /www.doctorswithoutborders.org/news-stories/specialreport/ bangladesh-violent-rackdownfuels-humanitariancrisis-unrecognized

2. Smith, M. (1995, December). The Muslim Rohingya of Burma. Paper presented at the Conference of Burma Centrum Nederland.

3. Imran, H. F. A. \& Mian, M. N. (2014). The Rohingya refugees in Bangladesh: A vulnerable group in law and policy. Journal of Studies in Social Sciences 8(2): 226-253.

4. Bangladesh point finger at Myanmar for Rohingya 'genocide'. Retrieved from: http://www.foxnews.com/ world/2018/09/27/bangladesh-point-finger-at-myanmarfor-rohingya-genocide.html

5. Bangladesh: Rohingya Refugee Crisis 2017-2018, Public Health Situation Analysis,7 May 2018, WHO (Regional office for South East Asia). Retrieved from: http:// www.searo.who.int/mediacentre/emergencies/ bangladesh-myanmar/public-health-situation-analysismay-2018.pdf?ua=1 